\title{
Development of Methodology for Applying Non-Violent Conflict Resolution in Academic Environment
}

\author{
Serhii Terepyshchyi \\ Doctor of Philosophical Sciences, Professor, National Pedagogical Dragomanov University \\ (Kyiv, Ukraine) \\ E-mail: terepyshchy@gmail.com \\ https://orcid.org/0000-0001-5506-0914
}

\begin{abstract}
Hleb Khomenko
Junior Research Fellow, PhD student (Philosophy), National Pedagogical Dragomanov

University (Kyiv, Ukraine)

E-mail: homenkoglib@gmail.com

https://orcid.org/0000-0003-2897-5400
\end{abstract}

The paper considers the problem of non-violent approaches application to conflict resolution in the academic area. To perform that, the method of conceptualization, inductive method and method of comparative analysis have been used. The basic functions of the mediator as a person who helps to solve the contradictions of conflict situation and facilitates the process of peacebuilding have been substantiated. The article emphasizes the importance of UNESCO activity in global supporting and spreading the ideas of tolerance as well as humanism. The authors propose a technique of non-violent conflict resolution based on the analyzed concepts of Mahatma Gandhi, John Dewey, Emmanuel Levinas, Marshall Rosenberg and others. The authors represent key factors of successful dealing with conflict through direct influence of universities and scholars.

This article is an attempt to describe the difference between the main goals of pacifism and nonviolence. It has been explained why people should stop perceiving education through the distorting lens of violence ideology and learn to see it in the mirror of the philosophy of non-violence. It has been discussed that violence against others is connected with violence against yourself as well as wrong strategies to meet personal needs. The sooner our society wants to understand the image of others, the fewer people will die for fake ideals. In this point there is a correlation between higher education, peace and conflict. Eventually it has been found that level of violence can be decreased through expression of empathy to all friends and haters in daily life and principled refusal from aggression.

Keywords: conflict, non-violence education, peace education, peacebuilding, critical thinking, empathic communication, emotional intelligence, tolerance

Received: August 30, 2019; accepted: September 17, 2019

(C) Terepyshchyi, Serhii, 2019

(C) Khomenko, Hleb, 2019 
Future Human Image, Volume 12, 2019: 94-103.

https://doi.org/10.29202/fhi/12/8

\section{Introduction}

The history of mankind has witnessed more than 2,500 wars that killed millions of people. In particular, more than 20 million people were killed in the World War I, and more than 50 million in the World War II, thereby turning the world into a huge cemetery [Royde-Smith \& Showalter, 2019]. The tragic fate of millions of people who were killed by war should have taught all succeeding generations to care for peace and harmony on a global scale and in each individual country as for the most important benefits necessary for normal functioning of the human race.

However, what is happening in the world today cannot be called a clear victory of peace over war. According to the Swedish Department of Peace and Conflict Studies in Uppsala (UCDP), there were 248 armed confrontations in 153 different countries within the period from the end of World War II to the first decade of the new era [Themner \& Wallensteen, 2012: 565]. The largest increase in the quantitative escalation of conflict situations was recorded in the period from 1946 to 1990 - from 17 to more than 50 mass cases of use of weapons. At the beginning of the $21^{\text {st }}$ century, a reverse process took place, leading to a substantial decrease in the number of "flashpoints" in the world community. In particular, in 2003, the number of military conflicts reached 30 , which is considered a positive trend in this issue, but does not in any way affirm a definitive victory over violence.

It is no secret that redistribution of public goods, their removal from some people and delivery to others is the main reason for most military conflicts of the current time, which is made possible by armed violence. Currently, these interests are hidden in the media by religious, ideological and geopolitical factors. On the other hand, one cannot but ignore the fact that in today's society there are powerful social forces interested in wars: racist groups, radical nationalists and fundamentalists, organized crime, while arms trafficking continues to be one of the most profitable exports businesses in the US, France, England, Russia, China, and several other countries. The Ukrainian scientist, a member of the Roman Club Volodymyr Gorbulin, has chosen quite accurate words for describing this situation in the world, calling the modern period in the society development a stage of "social turbulence", which requires finding the best solutions by joint efforts and their urgent coordination [Gorbulin, 2017: 468469].

\section{Theoretical and methodological approaches of research}

Based on the above considerations and backed up by certain information data, questions crucial to this work arise: is transformation of the culture of violence into the culture of peace utopia or a reality? And if this is still a reality, what place does the academic community take in this process? The above questions will be answered in the course of writing this work based on Emmanuel Levinas's dialogical thinking methodology, application of "Peace and Conflict Studies" tools, operation of quantitative and qualitative indicators of the Global Peace Index, as well as in-depth analytical activity of content of Peace Education magazine articles for 2017-2019. 
The purpose of this article is to develop a methodology for applying non-violent conflict resolution in an academic environment. Given on the number of scientific works devoted to the development of education under the conditions of conflict, as well as methods of non-violent interaction in the educational field, it becomes clear that this issue is really topical. At the same time, the question of understanding the nature of violence as such and ways of leveling it within the academic community remains open.

\section{Development of non-violence practice in philosophical interpretation}

Presenting the major material of the article, it should be noted that violence is ambivalent in its nature. On the one hand, it can be interpreted as part of human nature. Accordingly, one who seeks to eliminate violence is at odds with one's self by simply deceiving oneself. Contrary to this claim, there is a perception that a person is fully capable of defeating violence on a global scale. However, in order to achieve such an ambitious goal, each individual must reflect on the issue without attempting to justify the violence or deny its existence.

A significant contribution to the development of non-violence ideas was made by the philosophy of Gandhism, namely the famous doctrine called "Satyagraha", which from Sanskrit translates as a desire for truth. The philosophical doctrine of Gandhi appeals that any manifestations of evil and violence in the world are destructive because they give rise to discord between people and do not lead to a solution to a problem [Khomenko, 2015: 18$20]$. Because of this, the only fair way to overcome a conflict situation is goodwill of one person to another, to appeal to the conscience of the discussion participants over conflicting issues.

The German philosopher-irrationalist Friedrich Nietzsche once said: "Good is nothing more than the powerlessness of the weak" [Gongalo, 2011: 49]. Taking into account the philosophy of non-violence of Gandhi, the situation looks diametrically opposite: violence is a manifestation of the human spirit weakness, and goodness is a bright indicator of a strong personality. After all, while a weak-minded person accumulates insults and forms intentions for potential revenge, a thoughtful personality can forgive their enemies and even negotiate a mutually beneficial partnership with them.

In this context, it makes sense to mention the ideological work of the French philosopher Michel Serres, who considered the ability of people to pay attention to other points of view and to treat them in the same way as their own opinions to be the most valuable in building a nonviolent interaction. Moreover, a person who is capable of questioning every thought, regardless of its author's credibility or popularity, has immunity for a destructive behavioral strategy that results in violence. This ability in the scientific discourse of today has been referred to as the presence of critical thinking.

The main components of critical thinking are independence, reflectiveness, relevancy, consciousness and purposefulness. The critical thinking has its roots in the United States in the scientific work by William James and John Dewey. In this work, a particular attention should be paid to the achievements of the latter, who, as the founder of the philosophy of education, in his own work emphasized the role of the teacher in spreading the values of peace and nonviolence as the basis of constructive social behavior. It was Dewey who first emphasized that education should be implemented on an instrumentalist approach, refusing to use authoritarian teaching methods. The role of the teacher is to teach children in non-trivial ways that allow them to actively develop and express themselves. The teacher must not only speak about the 
value of peace in the classroom, but also believe in own words and reproduce the provisions of the philosophy of non-violence in teaching activity [Dewey, 2003: 181].

The British-Austrian Philosopher Carl Popper was in solidarity with the idea that the teacher, being a generator of non-violent ideas, should fulfill a peace-building mission. Education is not only about learning the facts, but also, above all, in showing how important it is to eliminate violence [Popper, 1994: 345]. In his view, people should stop perceiving education through the distorting lens of the ideology of violence and learn to see it in the mirror of the non-violence philosophy. Of course, solving a conflict and overcoming violence in a math or geography class is not an easy task. The teacher's mission in this situation is to encourage students to look at their daily practice in the light of the principles and methods of non-violence, to feel the boundary between constructive and destructive behavior in society, and to foster a culture of peaceful coexistence.

To be abusive in one's own actions means to have the desire to harm another person, to make someone suffer. But if we delve deeper into the nature of violence, it becomes clear that violence against others is linked to violence against oneself. After all, manifestation of violence excludes relationship on the basis of mutual recognition, which is necessary for any person for fulfilling life. Therefore, it is impossible to harm another person without harming yourself. A person who is in harmony with the world, a priori has no need to harm anyone in any way. For them another person is always a goal in itself, not a means of achieving another goal. It is known that this provision was the basis of Immanuel Kant's second imperative, the classic of German philosophy: "Act so that you treat humanity, whether in your own person or in that of another, always as an end and never as a means only" [Toftul, 2008: 26].

As defined by the UN General Assembly, the culture of peace and non-violence promotes respect for the life and dignity of every person without any prejudice and discrimination [UNESCO, 2001]. That is, the coexistence of people and peoples should be peaceful, without violence, but one should not be naive and hope for no conflict as such. The world cannot and will never be free from conflict, and the peace should be seen as a positive result of resolving conflicting precedents, rather than their nonoccurence. In this regard, pacifist views appear somewhat illusory because they stigmatize conflict and operate in such idealistic categories as forgiveness, reconciliation, and love. If the ideology of pacifism rests on the flight of fantasy, then the doctrine of non-violence takes into account the previous historical experience of the mankind, trying to build a society where human relations would be based not only on love but also on the ability to conquer conflict at a stage when it had not yet resulted in millions of human casualties.

Usually, the path to constructive conflict resolution begins with finding a favorable compromise. The concept of compromise is related to the idea of the negotiation process, when each party is ready to make concessions to its opponent in order to successfully resolve a particular conflict. First of all, compromise allows one to timely calm down any violence that has already exploded and resume communication between the opponents. Resumption of communication is a significant step towards further victory over the conflict. Accordingly, the ultimate goal of compromise is to create the conditions under which each of the parties to the conflict would not lose their dignity and partially achieve the desired result. The art of finding a compromise is to maximize the benefits for one side of the conflict and minimize the disadvantages for the other.

The French Philosopher Emmanuel Levinas made a rather interesting statement in his work that the man exists in this world only in relation to other people [Toftul, 2014]. Where there 
is no son there is no mother, where there is no leader there is no subordinate, etc. According to Levinas, building any relationship on the grounds of respect requires finding the optimal distance at which people can communicate with each other. The conditional positioning of one person in relation to another should take into account the level of their affinity, commonality of views, which will affect the personal needs of these persons in the best possible way.

Since the beginning of humanity, any bilateral relationship has been based on two established principles - gifting and exchange. Although today the man looks much more rational than they used to be, say, in the Early Paleolithic, the man cannot betray own nature and ignore corresponding instincts and impulses. Aggression as a prerequisite for violence is a kind of such instinct that is able to influence human behavior in many ways. In a metaphorical sense, aggression symbolizes the fire, which can bring both benefit and harm to the human individual.

However, aggression also does not come from nothing it is usually generated by other emotions and thoughts. Fear can be one of the most common feelings that trigger aggression. It can be both recognized by a person who is prone to violence and not recognized. By launching a survival instinct to give a person a natural ability for self-defense, fear can play a wicked joke by limiting the person's life to the eternal struggle with their fears, which have no objective reason. To immerse yourself in the intricacies of the mechanisms of overcoming your own fears means to go beyond the boundaries of this scientific work. Therefore, we would just like to point out that the violence of one person or another towards others is often accompanied by an irrational fear that can only be understood by the aggressor.

In other cases, violence stems from a boundless desire that meets the boundaries set by the desires of others. It is no longer about the natural needs that are inherent to each person and unite us into one, it's about individual desires. By others in this case we mean those whose wishes contradict, to say the least, my desires, whose interests are contrary to my interests, whose ambitions are inconsistent with my ambitions, their plans destroy my plans, their freedom threatens my freedom and their rights violate my rights. All of this, again, can give rise to fear in one's mind and a sense of uncertainty about one's future. The only effective way to overcome this conflict of interest is to transform the conflict, which reduces the distance between opponents, creating a positive atmosphere for their further cooperation on the basis of mutual respect and tolerance.

The French social philosopher and culturologist Rene Girard has developed a theory that sheds light on the causes of conflict and violence. According to the scientist, mimetic behavior or imitation leads to excessive competition, which, in turn, is the basis of any conflict. Contrary to the views of those who perceive imitation as a process focused on social harmony, Girard seeks to show that rivalry and conflict are at the heart of the issue of opposition and antagonism [Girard, 1972]. Mimetic behavior initiates a rivalry between people, which is realized through the appropriation of objects when several members of the group want to own a particular object at the same time. The validity of this scientific rationale can be traced observing the behavior of a young child who tries to appropriate other child's toys while playing in the yard. Reproducing Girard's concept in a domestic situation, it becomes clear that jealousy is one of the most powerful triggers of conflict between people.

In addition, a person's natural thirst for possession of objects determines the power over other people. "The world is ruled by the thirst for power, sex and hunger... The masses have never known the thirst for the truth. They demanded illusions without which they would not be able to live" [Freud, 1998: 532], - once said Sigmund Freud, who, among other things, was a supporter of pacifism. Such an assertion of the Austrian thinker is important in the context 
of this work, since it is impossible to construct a clear method of non-violent interaction in the academic environment without understanding the primary motives of the conflict that generate interpersonal aggression and various acts of violent nature.

However, we should not forget that desires have the property of being excessive, that is, they harm the person, not to mention those around. The French philosopher of Jewish descent, Simone Weil, who died during World War II, wrote in one of her works that desire requires more, far more than it needs. There is always a sense of unlimitedness in desire [Weil, 1963]. That is, the more a person satisfies own desires, the more control they gain over the person. This type of thinking has generally been characteristic of Buddhist philosophies who profess a frankly ascetic way of life.

It would be inappropriate to speak of giving up one's wishes in the modern world, given how economically profitable this industry looks. However, it is worth thinking about how significant this or that desire is for each individual person, whether it brings the person closer to freedom or slavery. One way or another, rivalry between people can only be overcome when each individual puts a constraint on own desires. As Sontag said, limited desires exist in harmony with the world; desires that contain something infinite, on the contrary [Weil, 1963].

Coming to the end of the discussion on the influence of human desires on behavioral responses, it should be emphasized that the most popular conflict of today is confronting the desires of a particular individual with the real conditions of their life. However, people who seek to satisfy only personal desires without respect for other people and their realities are doomed to constant conflicts with others. If a person's desire is to live in harmony with the world, in good relations with the members of the society, then the person will be able to build productive relations with others on the basis of mutual recognition. So in this situation it is worth avoiding the extremes, as in any other situation.

A person cannot run away from a conflict situation, giving up own rights as well as neglecting the rights of others. He or she must accept the confrontation because it is through conflict that a person is able to obtain the long-awaited peace of mind and recognition from others. Conflict itself can be developed both destructively and constructively. In the case of two children competing for the possession of a toy, the best way to resolve the conflict may be to involve a third party - a mediator. With a mediator the parties to the conflict can find new alternatives to resolve conflicting issues, and each side will be able to leave the conflict as a winner without losing own dignity.

\section{The role of education and the academic community in non-violence}

It is at this point of coordinates that the direct connection between philosophy, education and the academic environment is traced in the context of the non-violent approaches application in the process of conflict resolution. The fact is that the focus of the globalization culture of the modern society is inherent in the use of manipulative rhetoric, thus leaving its subjects only two alternatives in a conflict situation: cowardice or violence. In this case, the practice of violence is justified by the pursuit of contrived justice, illusory truth, and the like. Again, to resolve the conflict in a non-violent manner mediation is required.

Mediation is a third party involvement that interferes with the main parties involved in a conflict. The essence of mediation is to move from a two-way competition template to a threeway cooperation process. The main mission of the mediator is not only to be a listener to all parties to the conflict. It is realized by enabling each party to express their thoughts and feelings 
without the offending and intimidation of the opponent. The use of constructive rhetoric in the communication process of the parties to the conflict is the first and most important step to dispel misunderstandings and to find consensus between them. Based on these judgments, the activities of the mediator are designed to replace the confrontation between the two monologues, where each party hears only themselves, to a real dialogue in which every party has the desire to hear the other. The desire to hear an opponent has a therapeutic effect in itself, treats pain, reduces fears, soothes anger and mitigates covert violence.

A mediator does not have the authority to make final decisions or make a judgment. Their role in a conflict situation is impartial mediation, not arbitration. A mediator is a kind of facilitator that facilitates communication between a certain number of opponents so that they could reach mutually beneficial agreements. It can be argued that a mediator is not a neutral figure, but rather an unbiased speaker of moral standards who seeks to do justice to each party. In a sense, mediators tend to practice the art of maieutics (from the Greek maieutikê, "the art of midwifery"), since they help their wards produce "their own truth". Sometimes, to explain an ambiguous situation, it may not be sufficient to establish the objective truth of the facts. Therefore, firstly it will be appropriate to understand the subjective truth of the people involved in the conflict, their feelings, desires, disappointments, resentment and suffering.

In the context of developing a method of non-violent conflict resolution in the academic environment, one should pay attention to the method of non-violent communication, authored by the American psychologist Marshall Rosenberg. It is about changing the usual strategy of thinking and behavior toward empathy, expressing sympathy for one's opponents. Sympathy itself is a key aspect of productive cooperation in a conflict that can counteract a reactive response to a particular stimulus. Caring for your opponent is an effective behavioral strategy that can, on the one hand, reduce the conditional degree of tension between the opposing parties and, on the other, increase their level of interpersonal trust. With this method, the parties to the conflict can find a solution to conflicting situations with a "cool head", avoiding subjective assessments and biased criticism. The use of the language of facts, not an idle talk is also an important step towards overcoming a conflict [Rosenberg, 2003: 155-163].

In his own work, Rosenberg draws attention to the importance of using emotional intelligence in a conflict, namely, awareness of one's own emotions and feelings in each particular situation, as well as emotions and feelings of one's opponents. The American scholar asserts that there are no broadly defined conflicts at the level of a human individual needs and the ultimate eradication of violence is a real goal that can be realized through positive shifts at the personal, interpersonal and social levels [Rosenberg, 2003: 155-163]. It should be added that the method of non-violent communication is quite widespread in the diplomatic arena, in the education and business sectors. It is widely used in schools in Germany, Switzerland, Hungary, and has become extremely popular in US schools. In Ukraine, this method is practiced by the specialists of the Dialogue Facilitators Network and the representatives of public association of the Ukrainian Center for Non-violent Communication and Reconciliation — Prostir Hidnosti (Dignity Space).

The issue of awareness of own feelings and emotions in a conflict, which has already been emphasized in the previous paragraphs of this article, requires to be focused on additionally. The International Center for Non-violent Communication has been operating in Ukraine for several years. Its employees volunteer to work with children and young people affected by the Donbas war. The purpose of this center is to develop the emotional intelligence of young people who have not yet formed a stable system of ideological and value coordinates. Because 
of this, they are most in need of assistance in developing protective mechanisms that allow them to respond more carefully to traumatic factors of conflict situations.

According to the head of the center, certified trainer from Hungary Eva Rambala there is no conflict at the level of needs, they are universal for everyone. Conflicts arise at the level of strategies for satisfying them. Never give up on your needs, but be very flexible in strategies. When kids are fighting, you dont have to "beat" them with your words. If someone want peace and harmony in his family, he do not have to be the source of conflict himself. [Rambala, 2016]. Therefore, the essence of this approach is, again, in the ability to understand own feelings and needs, as well as possible feelings and motives of the diametrically opposite party. This, in turn, will make it possible to choose favorable strategies for engaging with the other party on the basis of empathy rather than animosity.

Another important aspect in the development of emotional intelligence is the responsibility of each individual for own feelings and thoughts. Rosenberg was in favor of the assertion that no person could make another feel a certain way [Rosenberg, 2003: 155-163]. This statement is quite questionable, given that our emotions and feelings are still to some extent dependent on external circumstances, the environment and the immediate environment. However, the American researcher resolves this contradiction in the following way: other people can be a trigger, but not the cause of our feelings. That is, another person may say or do something that evokes some negative emotions, but it is only up to us to be led by these emotions and be in thrall to them or not. As a result, when you focus on your inner self and take responsibility for your feelings, you have more options to make your own decisions.

In the academic environment, development of non-violent education is only starting to spread. In particular, the University of Peace in Costa Rica (UPEACE) has made a significant contribution to the promotion of non-violent conflict resolution mechanisms. On the basis of this university, the first master's program was initiated, which is dedicated to the development of peace education, not to mention the university's overall mission to support peacekeeping education. Albania plays an active role in educating human rights teachers and disseminating peace education ideas among countries in the European continent. With the support of UNESCO, which has created a nationwide network of sixty human rights experts who have taught local educators innovative methods of teaching the humanities, an educational project called "Democracy in Albania" is actively operating on the territory of this country.

In addition to experience of Costa Rica and Albania in this context, a project on non-violent education in Jordan should be highlighted as well. It brings together educational experts who discuss and develop concepts for non-violent education qualification events and implement them. A team of experts from Jordanian universities, with the support of German partners at the state level, is implementing appropriate training programs and strengthening the network of non-violent education in schools, universities, and in the framework of working with refugees [Nonviolent Education, 2017]. On the whole, the purpose of this project is clear enough - to promote a sustainable, constructive and positive transformation of a conflict in order to strengthen the core values of non-violence, tolerance, respect and participation in the Jordanian education system.

The most powerful influence on the development of non-violent discourse in the global dimension is exercised by UNESCO. With its support, new departments are opened each year at universities and academies of science, whose scientific work is devoted to the development of peaceful education in higher educational institutions. Promoting peace through education is at the heart of UNESCO's mission. UNESCO's approach to peace-building is multidimensional 
as it links education with a range of measures related to the root causes of violence, from human security to sustainable development. The purpose of UNESCO's educational programs and partnerships is to develop advanced education systems that embrace key values - human rights, intercultural understanding and tolerance. UNESCO promotes a culture of peace through a cross-industry platform. This platform includes five sectors: education, science, social sciences, humanities, culture, communication and information [UNESCO, 2008].

This entails a transformation of the national education system strategy, training of pedagogical staff, education policy specialists and teachers to enhance the potential of national institutions, improve curricula, revise and adapt textbooks and teaching materials. UNESCO provides various means of support: joint production of textbooks of two or more countries as a basis for mutual understanding, development of educational materials that are culturally and linguistically specific, support to member states that wish to review bilateral programs or multilateral programs and textbooks to eliminate prejudices or stereotypes.

In this regard, it should be noted that the dynamic organization of the physical and psychological systems of any person will be in its prime only when it is promoted by the inner peace. In other words, anyone can grow intellectually only if there is peace in the depths of their consciousness. Those guidelines that a student uses at school and a student uses at university will provide them with inner peace. The content presented in the curriculum through oral, auditory, symbolic, semantic and behavioral means should be the basis for peace of mind. Peaceful education can be developed within specific courses, but more importantly, it must be intertwined and interconnected with the curriculum itself. The university, as an academic community, must create a favorable climate in which everyone will feel safe, respect each other's opinions, and be able to resolve conflicts without neglecting other colleagues rights.

The idea of education as a means of developing a culture of peace and non-violence is reinforced by Gandhi's statement that if we are going to achieve peace in the world, we must start with children [Ward, 2011]. If trust and peace prevail in our schools and universities, young generations will be able to project a peaceful way of life on the whole society. You can practice peace through classroom training that encourages self-esteem, trust, collaboration, empathy, perseverance and celebration of differences.

The methodology of non-violent interaction in the academic environment should include the following recommendations addressed to all parties to the conflict:
a) keep track of your feelings and emotions;
b) express your thoughts without offending others;
c) refuse to use the language of ultimatums;
d) give another person a choice;
e) clearly justify your interests and needs;
f) do not forget about the needs of another person;
g) show sympathy for your opponent;
h) remember personal responsibility;
i) cast doubt, do not criticize;
j) respect your opponent's rights and dignity.

\section{Conclusions}

Thus, the academic community is an enabling environment for young generations to adopt effective communication strategies in conflict. Using the method of non-violent communication 
in discussions, all parties to a conflict situation can reach consensus by arousing compassion for the opponent, operating critical thinking and using emotional intelligence. Such findings suggest that education should seek to promote self-development of knowledge-seekers, not their subordination, without calling for passive obedience, but rather appealing to their personal responsibility, discipline, cooperation and solidarity with anyone who espouses humanistic values in the $21^{\text {st }}$ century.

\section{References}

Dewey, John. Democracy and Education. Lviv: Litopis, 2003 (in Ukrainian)

Freud, Sigmund. Introduction to psychoanalysis. Translated from German by Peter Tarashchuk. Kiev: Osnovi, 1998. (in Ukrainian)

Girard, Renee. Violence and the Sacred. Johns Hopkins University Press. 1972.

Gongalo, Vikentiy. Nietzsche phenomenon or «beyond good and evil». Journal of Buryat state university. 2011 (14): 48-53 (in Russian)

Gorbulin, Volodymyr The World Hybrid War: Ukrainian Forefront. Bulletin of the National Academy of Sciences of Ukraine. 2, 2017: 468-469. (in Ukrainian)

Khomenko, Hleb. Ethical and aesthetic tradition in national culture. Abstracts of the IV Student Scientific and Practical Conference, May 15, 2015: 18-20. (in Ukrainian)

Nonviolent Education in Jordan. Berghof Foundation. 2017 https://www.berghof-foundation. org/ru/programmes/peace-education-global-learning/nonviolent-education-in-jordan/

Official web-site of the University for Peace (UPEACE) https://www.upeace.org

Popper, Carl. Open Society and its enemies / Trans. from English. O. Kovalenko. - K.: Osnovi, 1994. - P. 444. (in Russian).

Rambala, Eva Ukraine crisis media center. 2016. http://uacrisis.org/ua/48341-spilkuvanna nenasylnytske

Rosenberg, Marshall. Nonviolent Communication: A Language of Life. Encinitas: PuddleDancer Press, 2003. p.155-163

Royde-Smith, John Graham, and Dennis Showalter. Encyclopedia Britannica. Killed, wounded, and missing, 2019. https://www.britannica.com/event/World-War-I/Killedwounded-and-missing

Themner, Lotta and Peter Wallensteen. Armed conflicts, 1946-2011. Journal of Peace Research, 49 (4), 2012: 565-575

Toftul, Mikhaylo Categories of good and evil. Bulletin of Zhytomyr State University. Issue 40, 2008: 26-31. (in Ukrainian)

Toftul, Mikhaylo. Levinas Emmanuel. Modern Ethics Dictionary. Zhytomyr: ZDU Publishing House. I. Franko, 2014. (in Ukrainian)

UNESCO's work on education for peace and non-violence: building peace through education. Digital library of UNESCO. 2008 https://unesdoc.unesco.org/ark:/48223/pf0000160787

Ward, Ashley. Developing a culture of peace and non-violence through education. Gandhi Research Foundation. 2011 https://www.mkgandhi.org/articles/peace4.htm

Weil, Simone. Susan Sontag. Selected essays. The New York Review of Books. Translated by Richard Rees. Oxford University Press, 1963. https://www.nybooks.com/ articles/1963/02/01/simone-weil/ 